\title{
COPING WITH WATER SUPPLY SHORTAGES IN MAJOR CITIES OF MALAWI
}

\author{
Effiness C. Mpakati-Gama ${ }^{1 *}$, Theresa Mkandawire ${ }^{2}$ \\ 1. School of Engineering and the Built Environment, Edinburgh Napier University, Edinburg, United Kingdom \\ 2. University of Malawi - The Polytechnic, Chichiri, Blantyre 3, Malawi
}

(Received: December 2014 / Revised: February 2015 / Accepted: April 2015)

\begin{abstract}
Urban water shortages continue to pose a threat to the livelihoods of many people in most developing countries including Malawi. In the past few decades, researchers and policy makers have focused on improving the performance of water utility infrastructure in order to eliminate this threat. However, little efforts have been made to understand social issues to water shortage and how people respond to them. Using a cross sectional survey and interviews in 11 townships in three cities of Malawi, the water supply disruptions and the study population's coping mechanisms to water shortage and frequent disruptions were investigated. This study aimed at understanding water shortage coping mechanisms and the implication on the income and health of the affected populations. The results suggest that while some people in areas affected by water disruptions spend huge sums of money to get water from alternative sources, others are exposed to health hazards. That is, circumstances force them to draw water from unsafe sources, hence, exposing themselves to diseases. The results imply that there is an urgent need to address water supply systems in order to pre vent people from impoverishment and water borne diseases.
\end{abstract}

Keywords: Coping mechanisms, Malawi, Urban Areas, Water Supply Disruptions

\section{INTRODUCTION}

Urban residents in most developing countries in Africa continue to face water supply shortages and resort to improvise unsustainable means to cope with the situation. Several factors are thought to contribute to the current shortage of water in urban areas. According to Vairavamoorthy et al. (2008), the decreasing level of raw water sources such as rivers, is considered as one of the main contributing factors to the current water shortages in most countries. In addition to this, Jacobsen et al. (2012) considers that there has been poor performance of institutions established to manage water distribution in the past five decades and this is regarded as another major factor causing water shortages. However, these factors are exacerbated by the increasing demand of water due to rapid rise in urban population in cities. The rising population exerts pressure on water distribution systems and structures originally constructed for smaller populations.

Like in other countries, cities in Malawi are experiencing water shortages due to the rising urban population. Figures in Table 1 show that urban population has been rising in the major cities of Lilongwe, Blantyre and Mzuzu between 1998 and 2008 (National Statistics office (NSO), 2008). Taking Blantyre city as an example, water demand has increased from $78,000 \mathrm{~m}^{3} /$ day to $85,000 \mathrm{~m}^{3} /$ day (Vazquez, 2009).

"Corresponding author. E-mail: e.mpakati-gama@ napier.ac.uk 
According to Vazquez (2009) Blantyre Water Board (BWB) served 920,000 households, far beyond the intended population at its first establishment in 1929. Projections by NSO suggest that the population in Lilongwe and Blantyre will be over 2 million, respectively, by 2020 . This implies that water demand will continue to rise in urban areas in the foreseeable future.

Table 1. Population in major cities of Malawi

\begin{tabular}{|c|c|c|c|c|c|c|c|c|c|}
\hline \multirow[t]{2}{*}{ City } & \multicolumn{4}{|c|}{ Population $\left(* 10^{3}\right)$} & \multirow{2}{*}{$\begin{array}{c}\text { Annual } \\
\text { growth } \\
\text { rates }(\%)^{\mathrm{b}} \\
1998- \\
2008\end{array}$} & \multicolumn{3}{|c|}{$\begin{array}{c}\text { Population Density } \\
\left(\text { people } / \mathrm{km}^{2}\right)\end{array}$} & \multirow[t]{2}{*}{$\begin{array}{r}\text { Area } \\
\left(\mathrm{km}^{2}\right)\end{array}$} \\
\hline & 1987 & 1998 & 2008 & $2020^{\mathrm{a}}$ & & 1987 & 1998 & 2008 & \\
\hline Blantyre & 333 & 502 & 661 & 1,275 & 2.8 & 1,514 & 2,282 & 3,007 & 220 \\
\hline Lilongwe & 223 & 440 & 669 & 1,324 & 4.3 & 490 & 966 & 1,467 & 456 \\
\hline мzиzи & 44 & 87 & 128 & 270 & 4.0 & 921 & 1,812 & 2,676 & 48 \\
\hline
\end{tabular}

${ }^{\text {a }}$ Projected population

${ }^{\mathrm{b}}$ Intercensal population growth rate

The literature demonstrates that decision makers in developing regions such as subSahara Africa (SSA) have been striving to find solutions to urban water shortages due to the rising concerns on the growing sanitation and economic issues related to the people affected (Chikava, 2013; Jimenez-Redal, 2014; Hirvi and Whitfield, 2015). Similarly, urban residents have also come up with their own solutions which vary from place to place and among people in the same localities. In their study conducted in a slum area in Kenya, Chikava et al. (2014) observed that people considered private boreholes as one of the solutions despite not being able to address cost issues. Researchers have also suggested water recycling, reuse and rain water harvesting as alternative ways for addressing water supply issues affecting urban residents in some parts of Africa (Leas et al., 2014). Despite severe urban water issues prevalent in cities of Malawi, some of which are documented by Mughogho and Kosamu (2013); Kalulu and Hoko (2012); UN-Habitat (2011a, b \& c), little attention has been given to understand how people affected by water shortages cope, and the implications of water shortage on their livelihood focusing on income and health aspects.

This paper presents findings of a feasibility study to explore and compare mechanisms that people use to cope with water shortages and water supply disruptions in 3 major cities of Malawi, namely Blantyre, Lilongwe and Mzuzu. Although the paper does not suggest alternative coping solutions at this stage, the approach used and the results highlight the implications of these coping mechanisms on peoples' income and health, and is a good basis for indulging into further studies in Malawi or other countries with water supply issues.

\section{METHODOLOGY}

A triangulation approach involving literature review, community interviews and water flow recordings was used as major source of information. The literature review covered published journal articles and reports, unpublished reports and government policies relating to water distribution in Malawi. Community interviews were conducted in 11 townships across the three main cities of Malawi (Blantyre, Lilongwe and Mzuzu) as illustrated in Table 2. Malawi has four cities, out of which three were considered in the study because of high urbanisation rates. In total 55 interviews were conducted with purposely sampled community members to reflect the heterogeneity of the population, based on their income status. In addition, recordings of water supply interruption were made in purposefully selected townships in the three cities from $1^{\text {st }}$ to $31^{\text {st }} \mathrm{July}, 2012$. The unstructured open ended 
interviews were conducted to obtain information regarding water sources used, consistency of water supply from the sources used, major problems faced and how residents cope with water supply shortages if any. Five community members, who had lived in the same township for ten years or more were interviewed in each township to obtain the required information.

Table 2. Townships focused on and settlement type

\begin{tabular}{ccccc}
\hline City & Medium & High & High & Slum \\
& density & density & density & Area \\
& PHA & PHA & THA & \\
\hline \multirow{4}{*}{ Blantyre } & & Kanjedza, & Golio, & Misesa, \\
& & Nkolokosa & Chilobwe & Zambia, \\
Lilongwe & New Naperi & & & Ntopwa \\
Mzuzu & Area 47 & - & Area 23 & - \\
\hline
\end{tabular}

\section{RESULTS AND ANALYSIS}

The results are presented in three major themes based on the objectives of this study; water supply by settlement type, water supply consistency within individual cities and water shortage coping mechanisms.

\subsection{Water Supply By Settlement Type}

The literature highlights that water infrastructure and the extent of water flow interruption in all cities of Malawi vary with settlement type (Kruse and Manda, 2005); UNHABITAT, 2010. For instance, the levels of services follow the settlement classification established during the British colonial era in the mid-1900s. That is, Permanent Housing Areas (PHAs) contain fully developed infrastructure networks of water, electricity and roads. According to town planning by-laws, houses in PHAs need town planning approval and only permanent building materials such as kiln burnt bricks for walls and iron sheets for roofing are allowed. PHAs are subdivided into high, medium and low density categories. On the contrary, in Traditional Housing Areas (THAs), developers are allowed to use any building materials and are partly serviced in terms of road, water and electricity infrastructure. Finally, in squatter settlements, developers use different materials depending on their affordability and sense of security on the illegally occupied lands. No infrastructure services are provided in these areas apart from what the residents may develop once permanently settled.

\subsection{Water Consistency Within Individual Cities}

The results show that water supply was inconsistent from one Township to the other within the same city. For instance, Figure 1 shows an average of 13 hours of water shortage in Kanjedza Chilobwe, 6.23 hours, New Naperi 0.27 hours and Nkolokosa 3.01. The results show that New Naperi Township recorded the lowest hours of no water supply while Kanjedza Township recorded the highest number of hours of no water supply per day.

Residents in Golio and Ntopwa Townships did not own water taps. Therefore, they were not asked to record water flows. In Lilongwe city, residents in Area 47 did not experience water supply shortages during the study period while in Area 23 they experienced water shortages on average 3 hours per day. Residents from Chibanja Township in Mzuzu city did not report water shortages throughout the study period. 
Figure 1. Average water supply shortages per day

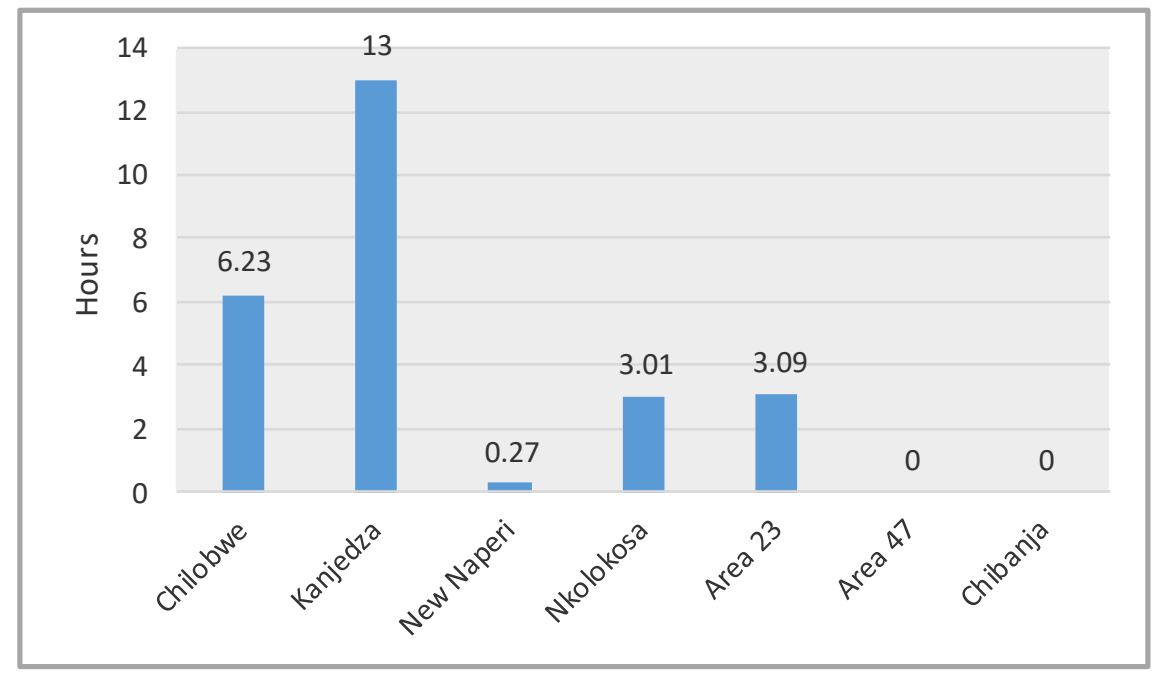

\subsection{Water Shortage Coping Mechanisms}

Regarding coping mechanisms, there is evidence that residents in the listed Townships used various methods to cope with the water shortages. As illustrated in Table 3, residents in Misesa, Zambia and Ntopwa utilised any water resources available within their neighbourhoods, purchased water from the neighbouring homes owning water taps and used water streams to wash clothes and other home utensils. Considering they have no water taps in their homes, this is their normal life to cope with water supply problems.

Respondents in THAs also used a wide range of methods when there was no water supply in the communal taps they use. For instance, Golio THA Township residents indicated that water was purchased from wells and boreholes in the neighbourhood. They also collected water from the near-by Nasolo River. At times residents wash their clothes and kitchen utensils along the river banks instead of taking the water home. Similar to the people living in slums, residents in Golio Township had no communal water taps working. In another THA Township, Chilobwe, residents reported that water was drawn from Chimwankhunda River. Chilobwe residents also reported that they purchased water from privately owned wells and that washing of household utensils and clothes was done along the water sources available in the area. The residents of Chilobwe and Area 23 THAs also highlighted that they used water stored in buckets when water was unavailable.

In high density PHA of Kanjedza, their main coping methods included the use of water that they stored in buckets, water purchased from privately owned borehole at a nearby primary school and water purchased from neighbouring locations throughout the month. In contrast, residents in Nkolokosa high density PHA obtained water from friends and relatives and purchased water in the neighbouring Townships. Unlike Kanjedza residents who hired people to bring the purchased water to their houses, one of the Nkolokosa residents mentioned that their car was used for transporting the water to their home. Two of the residents interviewed in Nkolokosa also highlighted that water is usually stored in buckets for use when water supply is insufficient.

Finally, residents in New Naperi medium density PHA highlighted that they did not do anything during the periods when water supply was disrupted as their period of no flow was very minimal. Some Naperi residents had water storage tanks which were used when there was no flow from water utilities. Measures to resolve the water supply problems are decided upon depending on how long it takes for the water flow to resume. Measures often used include driving to friends' or relatives' homes to fetch water. One resident however, indicated that the water storage tank installed within their premises would serve as a supply 
source if water supply shortage would persist. In Area 47 where they had no water shortages in the month of the study, no coping mechanisms were mentioned. The residents also mentioned that the problem rarely occurs, and when it does happen, it takes about 2 hours or a maximum of a day in month. Considering they are aware of the duration, they simply wait for the supply to be reinstated. One resident in Area 47 in Lilongwe had this to say:

"Although the area rarely faces water outages some inconveniences do occur when the water supplier is carrying out maintenance works. However, warnings are issued as to when these routine works will occur. The short supply period normally last for a minimum of two to 2 hours or a maximum of a full day. And if they occur, it will be either a Tuesday or Thursday between 6:00 and 8:00 pm".

Table 3. Coping methods in the studied locations

\begin{tabular}{|c|c|c|c|c|c|c|c|}
\hline \multirow{2}{*}{ Township } & \multirow{2}{*}{$\begin{array}{l}\text { Location } \\
\text { Type }\end{array}$} & \multicolumn{6}{|c|}{ Water sources used during disruptions } \\
\hline & & $\begin{array}{l}\text { Bucket } \\
\text { water } \\
\text { storage }\end{array}$ & $\begin{array}{l}\text { Purchase } \\
\text { in the } \\
\text { neighbourhood }\end{array}$ & $\begin{array}{l}\text { River or } \\
\text { stream/ } \\
\text { unprotected } \\
\text { well }\end{array}$ & $\begin{array}{l}\text { From } \\
\text { relatives }\end{array}$ & $\begin{array}{l}\text { Water } \\
\text { tank }\end{array}$ & $\begin{array}{l}\text { Protected } \\
\text { private } \\
\text { well or } \\
\text { borehole }\end{array}$ \\
\hline Area 47 & $\begin{array}{c}\text { Medium } \\
\text { density }\end{array}$ & - & - & - & - & - & - \\
\hline Area 23 & THA & $\mathbf{x}$ & $\mathbf{x}$ & - & - & - & - \\
\hline Chibanja & THA & - & - & - & - & - & - \\
\hline Chilobwe & THA & $\mathbf{x}$ & $\mathbf{x}$ & $\mathbf{x}$ & - & - & - \\
\hline Golio & THA & $\mathbf{x}$ & $\mathbf{x}$ & $\mathbf{x}$ & - & - & $\mathbf{x}$ \\
\hline Kanjedza & PHA & $\mathbf{x}$ & $\mathbf{x}$ & - & - & - & $\mathbf{x}$ \\
\hline Misesa & Slum & $\mathbf{x}$ & $\mathbf{x}$ & $\mathbf{x}$ & & & \\
\hline $\begin{array}{l}\text { New } \\
\text { Naperi }\end{array}$ & $\begin{array}{c}\text { Medium } \\
\text { density }\end{array}$ & - & - & - & - & $\mathbf{x}$ & - \\
\hline Nkolokosa & PHA & $\mathbf{x}$ & $\mathbf{x}$ & - & $\mathbf{x}$ & - & - \\
\hline Ntopwa & Slum & $\mathbf{x}$ & $\mathbf{x}$ & $\mathbf{x}$ & - & - & - \\
\hline $\begin{array}{l}\text { Zambia } \\
\text { (Ndirande } \\
\text { Township) }\end{array}$ & Slum & $\mathbf{x}$ & $\mathbf{x}$ & $\mathbf{x}$ & - & - & - \\
\hline
\end{tabular}

See appendix A for detailed information.

\section{DISCUSSION}

The results from the feasibility study highlight that water supply consistency differ from one city to another just as the institutions that supply and manage water in the respective cities are different. However, what is not clear is whether the extent of the variations in water supply interventions and factors that cause them is associated with the supply institution in respective cities.

The findings of the study also imply that there are disparities in water supply and interruptions between townships in each city except for Mzuzu where residents in both townships did not experience any water shortages in the month the recordings were made. The results explicitly show that water supply interruption in Blantyre and Lilongwe are dependent on the type of location. For instance, Area 23 in Lilongwe is a densely populated location, and most people are of very low income status (UN-HABITAT, 2011b). However, the figures show that they faced more water interruptions as opposed to those who are from high income status area in Area 47 Township. Paradoxically, people from high income groups have better coping mechanisms, including installation of high capacity water storage tanks. Moreover, they can afford easy transportation of water from neighbouring towns if needed. The results suggest that people from low income Townships are more affected by water interruption than those from high income areas. The results also indicate that the people 
in high income locations have flexible coping mechanism considering the water problems are not persistent compared to those in low income areas.

One of the major goals of local MDGs in Malawi is to ensure there is access to a water supply within a distance of $500 \mathrm{~m}$ for all the people in the country. The medium and long-term goal for the second Malawi Growth and Development Strategy (MGDS II) is to ensure that water resources are well protected and managed to meet agricultural, domestic, and industrial demands. However, problems remain as to how to assess the water resources. For instance, about $30-40 \%$ of the supplied water points in peri-urban and rural areas in Malawi were recorded not functional (Mandowa, 2005). Moreover, some water points are too far apart than the $500 \mathrm{~m}$ distance recommended by the World Health Organisation (WHO). Consequently, alternative supplies are improvised but their quality is often below the required standards.

As noted from the results, water supply shortages in different Townships led residents to adopt ways of coping with the situation. Unfortunately, some of the coping mechanisms may have short and long term health and affordability related implications on the livelihood of those affected. From the health point of view, for instance, the use of water from unprotected wells and rivers in THAs and the squatter areas will exacerbate the prevalence of water borne diseases already affecting most people in the urban areas of Malawi. Similarly, storing of water in buckets, has health implications considering that sometimes water overstays in the buckets which can be a health hazard to consumers. That is, there are possibilities of the water getting contaminated through storage systems used and use of inappropriate storage system and cause diseases.

However, for the same health reason, people waste water when they get rid of the stored water to opt for fresh water when flow resumes. This leads to another problem of water wastage and hence, unbudgeted expenses considering that all the means used to get water incur costs. In Kanjedza Township for instance, the costs incurred for alternative means were in two-fold, costs for purchasing and for transporting the water to their respective homes.

Costs related to water purchasing in slum areas and THAs, particularly in Golio Township are exacerbated by the lack of tap water in most homes. Purchasing small quantities of water from kiosks and neighbouring places is costly to most residents. According to the respondents in Zambia location in Ndirande Township, a 20 litre bucket of water cost about MK5.00 when the survey was conducted. This translates into a total expenditure of MK525 (US\$31) per week for an average family of five people using an average of 30 litres per capita per day (Current exchange rate is about US $\$=M K 480$ due to the devaluation of the Malawi Kwacha). The new findings contradicted by far the estimates made by Foster \& Shkaratan (2011) that 25 litres per day is adequate for a family of five. In Golio area, where the BWB communal water kiosks are no longer operational due to managerial problems, as previously highlighted by Vazquez (2009), long distances to fetch clean water for drinking and cooking is another issue.

Chikava (2013) and Hirvi and Whitfield (2015) highlighted similar health and economic implications in their studies which also include how people in other parts of the SSA are affected by the regular water interruptions. The studies illustrate how people address the water issues affecting them. For instance, in a study conducted by Chikava et al. (2014) in a slum area of Kenya, people considered private boreholes as one of the best solutions. Similar efforts have been employed in Ndirande (Golio) location in Malawi, but proved a failure. Thus, although private management of water kiosk has been recommended by Malawi Social Action Fund (MASAF) as one of the ways of promoting community participation and ownership of such projects, poor management of the kiosks provide loopholes for rising costs of water purchased through this system according to the 
information gathered from residents in Golio Township. The resident said that the MASAF kiosk had always been moved from one plot to another due to the administrative issues that kept arising. At the time of this survey, a kiosk was being planted in the neighbourhood (Figure 2) under the MASAF initiative but it was meant to be run by a local resident.

Other problems with the kiosks can be evidenced in Figure 2 regarding poor location of the water kiosk. The kiosk was planted next to a pit latrine as well as a road side drainage which are potential sources of water pollution. Although no information is available on the state of the water in the Township, apart from that of Nasolo river (Maoulidi, 2012), a study in Bangwe Township in Blantyre, found that water used in the four villages sampled did not meet the World Health Organisation and Malawi Bureau of Standards guideline values in terms of feacal coliform count, $\mathrm{pH}$ and conductivity (Kaonga et al., 2013). However, similar outcomes would be expected in most THAs where pit latrines are commonly used.

Considering the disruptions occurring in the main cities of Malawi, further interventions have to be explored on how people affected by water shortages cope, and the implications of water shortage on their livelihood in terms of loss of income and poor health.

Figure 2. New kiosk under construction in Golio THA

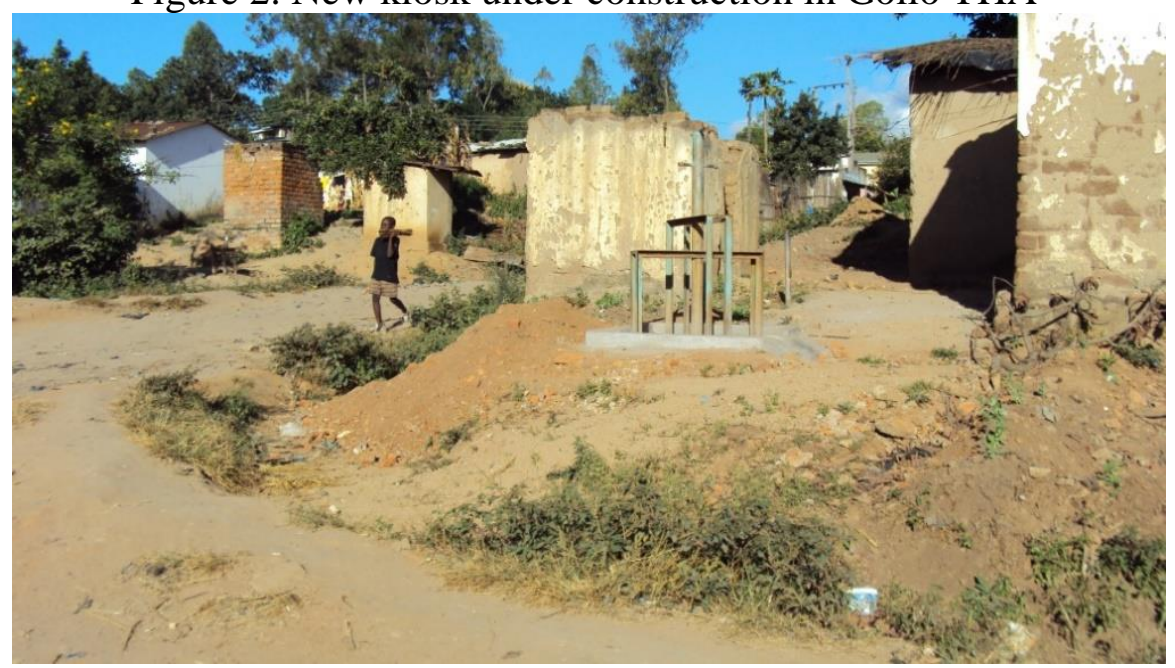

\section{CONCLUSION}

Water is one of the basic human needs. In urban areas of Malawi, water supply problems are due to a combination of factors related to the performance of the water utilities and the rising demand. This paper presents findings of a feasibility study on how urban residents respond to water shortages in three major cities of Malawi. The results indicate that water supply was inconsistent in all the Townships. Overall, the results demonstrate that the high density areas are the most underprivileged. There were also disparities between Townships within the same cities. These results demonstrate that the supply obstruction is dependent on the location. This study also demonstrates that the residents use several mechanisms to cope with water supply interruption and shortage including purchasing of water from water kiosks, private homes and drawing water from unprotected sources such as wells and rivers. Despite the limitation of this feasibility study in relation to the number of locations included and short data collection period, the study raises important issues that can be explored further in future studies. The future studies therefore need to include as many locations and evaluate water flows in different months of the year. Further and urgent research in this area should focus on the extent of the health and income implications of persistent water supply interruptions. 


\section{REFERENCES}

Chakava, Y. (2013). "Transition Phase" water supply interventions in low-income urban settlements: Kenya. Ph.D.thesis, retrieved on 20 February 2015 from https://dspace.lib.cranfield.ac.uk/handle/1826/8475

Chakava, Y., Franceys, R., \& Parker, A. (2014). Private boreholes for Nairobi's urban poor: The stop-gap or the solution? Habitat International, Volume 43, pp. 108-116.

Foster, V., \& Shkaratan, M. (2011), Malawi's Infrastructure: A continental perspective. Policy Research Working Paper number 5598, World Bank, Africa Region, Sustainable Development Department, Washington DC.

Hirvi, M., \& Whitfield, L. (2015). Public-Service Provision in Clientelist Political Settlements: Lessons from Ghana's Urban Water Sector. Development Policy Review, Volume 33 Number 2, pp. 135-158.

Jacobsen, M., Webster, M., \& Vairavamoorthy, K. (Eds.). (2012). The future of water in African cities: Why waste water? World Bank Publications.

Jimenez-Redal, R., Parker, A., \& Jeffrey, P. (2014). Factors influencing the uptake of household water connections in peri-urban Maputo, Mozambique. Utilities Policy, Volume 28, pp. 22-27.

Kalulu, K., \& Hoko, Z., (2010), Assessment of the performance of a public water utility: A case study of Blantyre Water Board in Malawi. Physics and Chemistry of theEarth A/B/C, Volume 35, pp. 806-810.

Kruse, C., \& Manda, M. A. (2005). Lessons in urban management: experiences in Malawi, 2000-2005. Mzuzu: ALMA Consult.

Leas, E.C., Dare, A., \& Al-Delaimy, W. K. (2014). Is gray water the key to unlocking water for resource-poor areas of the Middle East, North Africa, and other arid regions of the world? Ambio, Volume 43, Number 6, pp. 707-717.

Mandowa, W. (2005). Rapid assessment of Malawi rural water supply and sanitation. Final Draft Report for ADB.

Maoulidi, M. (2012). Water and sanitation needs assessment for Blantyre City, Malawi. MCI, Social sector working paper series No. 27/2012. New York, Millennium Cities Initiative, Columbia University Earth Institute. Retrieved on 09 February, 2015 from http://mci.ei.columbia.edu/files/2014/04/27_Blantyre-WatSan-NA-Oct20111.pdf

Mughogho, B. G., \& Kosamu, I. M. (2012). Water supply arrangements in developing countries: A case study of Blantyre City, Malawi. African Journal of Environmental Science and Technology, Volume 6, Number 2, pp.94-103.

National Statistical Office of Malawi (NSO) (2008), retrieved January 30th, 2015, from 2008 Population and Housing Census, Household and Housing Conditions Report: http://www.nso.malawi.net

UN-HABITAT, (2010), Malawi Urban Housing Sector Profile, Nairobi: UN-HABITAT.

UN-HABITAT, (2011a), Malawi: Blantyre Urban Profile, UN Habitat, Regional and Technical Corporation Division, UN - HABITAT, Nairobi.

UN-HABITAT, (2011b), Malawi: Lilongwe Urban Profile. UN Habitat, Regional and Technical Corporation Division, Nairobi: UN - HABITAT.

UN-HABITAT. (2011c). Malawi: Mzuzu Urban Profile. UN Habitat, Regional and Technical Corporation Division, Nairobi: UN - HABITAT.

Vairavamoorthy, K., Gorantiwar, S.D., \& Pathirana, A. (2008). Managing urban watersupplies in developing countries-climate change and water scarcity scenarios. Physics and Chemistry of the Earth, Parts A/B/C, Volume 33, Number 5, pp. 330-339.

Vazquez, V. (2009).Water and sanitation needs assessment for Blantyre City, MalawiMCI, Social sector working paper series No. 03/2009. New York, Millennium Cities Initiative, Columbia University Earth Institute. 
Appendix A

\begin{tabular}{|c|c|c|}
\hline Township & $\begin{array}{l}\text { Location } \\
\text { type }\end{array}$ & Water shortage coping methods used \\
\hline Area 23 & THA & $\begin{array}{l}\text { 1. Purchased from neighbouring townships } \\
\text { 2. Always store water in buckets }\end{array}$ \\
\hline Area 47 & $\begin{array}{l}\text { Medium } \\
\text { density }\end{array}$ & Not applicable \\
\hline Chibanja & THA & Not applicable \\
\hline Chilobwe & THA & $\begin{array}{l}\text { 1. Purchased water from taps in neighbouring Chimwankhunda } \\
\text { township } \\
\text { 2. Water drawn from Chimwankhunda river and other } \\
\text { surrounding water streams } \\
\text { 3. Laundry done along available water streams } \\
\text { 4. Purchased water from privately owned wells in the } \\
\text { neighbourhood } \\
\text { 5. Water always stored in buckets }\end{array}$ \\
\hline Golio & THA & $\begin{array}{l}\text { 1. Purchased water from neighbours with water taps } \\
\text { 2. Water drawn from Nasolo river } \\
\text { 3. Do laundry and cleaning of utensils in Nasolo river } \\
\text { 4. Purchase water from privately owned MASAF (Malawi Social } \\
\text { Action Fund) kiosk within the neighbourhood }\end{array}$ \\
\hline Kanjedza & PHA & $\begin{array}{l}\text { 1. Water always stored in buckets and drums } \\
\text { 2. Purchased water from a privately owned borehole by using } \\
\text { hired labour } \\
\text { 3. Purchased water from neighbouring locations }\end{array}$ \\
\hline Misesa & Slum & $\begin{array}{l}\text { 1. Purchased water from neighbouring townships } \\
\text { 2. Purchased water from surrounding privately owned unprotected } \\
\text { wells } \\
\text { 3. Water drawn from surrounding streams of water } \\
\text { 4. Laundry done along available water streams }\end{array}$ \\
\hline
\end{tabular}

\begin{tabular}{|c|c|c|}
\hline $\begin{array}{l}\text { New } \\
\text { Naperi }\end{array}$ & $\begin{array}{l}\text { Medium } \\
\text { density }\end{array}$ & Water available in privately owned water tank \\
\hline Nkolokosa & PHA & $\begin{array}{l}\text { 1. Purchased water from neighbouring townships } \\
\text { 2. Water fetched by car from friends and relatives in neighbouring } \\
\text { townships } \\
\text { 3. Water always stored in buckets }\end{array}$ \\
\hline Ntopwa & Slum & $\begin{array}{l}\text { 1. Purchase water from neighbouring homes } \\
\text { 2. Purchase water from privately owned unprotected wells } \\
\text { 3. Do laundry and cleaning of utensils in surrounding water } \\
\text { streams }\end{array}$ \\
\hline $\begin{array}{l}\text { Zambia } \\
\text { (Ndirande } \\
\text { Township) }\end{array}$ & Slum & $\begin{array}{l}\text { 1. Purchase from neighbouring locations } \\
\text { 2. Purchase water from privately owned protected and } \\
\text { unprotected wells } \\
\text { 3. Do laundry and cleaning of utensils in surrounding water } \\
\text { streams }\end{array}$ \\
\hline
\end{tabular}

